\title{
Reliability of Sports Medical Solutions Handgrip and Jamar Handgrip Dynamometer
}

\author{
Stefan Marković ${ }^{1}$, Milivoj Dopsaj ${ }^{1,2}$, Veljko Veljković ${ }^{3}$ \\ ${ }^{1}$ Faculty of Sport and Physical Education, University of Belgrade, Blagoja Parovića street 156, 11030 Belgrade, Serbia. \\ stephan.markovic@hotmail.com \\ ${ }^{2}$ Institute of Sport, Tourism and Service, South Ural State University, Sony Krivoy street 60, 454080 Chelyabinsk, Russia. \\ ${ }^{3}$ Biomed Protection, Galveston, Texas, TX, 77550, USA.
}

\begin{abstract}
The aim of this paper is to determine inter-reliability, concurrent validity, and interchangeability of the SMS HG dynamometric system and a Jamar digital dynamometer for hand grip strength measurements performed in two relevant positions of the elbow joint, i.e. $90^{\circ}$ flexion and $180^{\circ}$ (full) extension. The sample in this research consisted of 61 participants and included 27 women and 34 men. Statistically significant differences in the results found between two positions in the elbow joint indicate that the results must be evaluated separately. However, regarding both testing positions, i.e. $90^{\circ}$ flexion and $180^{\circ}$ extension in the elbow joint, it was determined that SMS HG and Jamar instruments have a very high level of inter-reliability (ICC 0.948 to 0.980 ), but lack concurrent validity. The established mean difference of the results was higher for the $90^{\circ}$ than for the $180^{\circ}$ position but in both cases was considered to have a practical significance, thus not supporting the interchangeability of the instruments.
\end{abstract}

Keywords: handgrip strength, dynamometry, strain gage, digital dynamometer, elbow angle.

\section{INTRODUCTION}

Hands can be considered a highly specialized, manipulative organ of the human body involved in different tasks with various physical objects, thus capable of exerting a variable level of muscle force depending on the type of load and its intensity. Muscle strength is often equated with muscle force and can be defined as the ability of a muscle or a group of muscles to produce force while contracting against external resistance [1]. The isometric dynamometry method is used to determine the maximal force that can be produced during a concentric voluntary contraction against a supramaximal load or resistance, i.e. the maximal contractile potential of a muscle. In clinical and sports settings different dynamometric systems are used in order to determine the produced amount of force or torque force [2].

Handgrip strength is considered a limiting factor in all manipulative tasks performed by the cranial part of the body [3]. When measured properly it can provide objective and quantifiable information about hand function [4] and provide an index of the functional integrity of the upper extremity [5]. Furthermore, handgrip strength is positively related to other muscle groups [6], so it is widely used as an indicator of overall body strength in children, adolescents, and adults [7]-[9], an integral part of basic test batteries used in sports [10]-[12] and even a robust marker of general health status [13].
The quantitative measure of handgrip strength can be obtained using a dynamometer [14], but the diverse range of assessment protocols, testing positions, and instruments makes a comparison of the results fairly difficult and impractical so the selection of the most appropriate approach is usually considered within the context of the purpose of the assessment [15]. The most widely used instrument that is considered a gold standard for handgrip testing and evaluation is the Jamar dynamometer with an adjustable handle that measures grip strength in kilograms or pounds of force [15]. However, current hardware and software allow utilization of more sophisticated systems [2], [12] and a deeper analysis of relevant contractile, i.e. functional, characteristics of the tested muscle groups. Modern measurement systems implementing a strain gage as an element of the measuring chain measure applied force in newtons and are commonly used in clinical and especially sports praxis for evaluation of contractile characteristics of different muscle groups [6], [12], [16] including flexor muscles of the hand [17]. A typical example of the strain gage based measurement system used for acquisition and analysis of the force signal, i.e. for evaluation of relevant contractile properties of different muscle groups [6], [10], [12], [16], [17] is the commercially available SMS HG (Sports Medical Solutions Handgrip). 
As previously mentioned, the testing position influences the obtained results, which is also true in relation to the position, i.e. the angle, in the elbow joint [18]. Previous research has determined that significantly lower handgrip strength scores are produced in $90^{\circ}$ flexion than in full extension in the elbow joint [4], [5], [18], [19], which is contrary to other results that indicate higher maximal strength in $90^{\circ}$ flexion in the elbow joint [20], [21]. To sum up, these conflicting findings are inconclusive. On the other hand, functional dimorphism, i.e. strength asymmetry in relation to hand dominance [10], has been well established.

In relation to all aforementioned, the aim of this paper is to compare the Jamar handgrip digital dynamometer and the SMS HG strain gage dynamometric system and to determine their concurrent validity, inter-instrument reliability, and interchangeability in different positions of the elbow joint, taking into account the functional strength asymmetry related to hand dominance.

\section{METHODS}

The basic method used in this research was laboratory testing. All research data was acquired using the dynamometry method. The study was conducted according to the standards for research methods in sports [22].

\section{A. The research sample}

The sample in this research consisted of a total of 61 participants who were on average $34.2 \pm 13.3$ years old, had a mean body height of $176.4 \pm 9.5 \mathrm{~cm}$, and mean body weight of $75.6 \pm 15.2 \mathrm{~kg}$. The sample included 27 women (Age: $34.9 \pm 12.6$ years; Body Height: $168.1 \pm 5.8 \mathrm{~cm}$; Body Weight: $63.2 \pm 7.6 \mathrm{~kg}$ ) and 34 men (Age: $33.5 \pm 14.0$ years; Body Height: $183.1 \pm 6.0 \mathrm{~cm}$; Body Weight: $85.5 \pm 12.1 \mathrm{~kg})$. Of the overall sample, 59 participants were right-handed and 2 were left-handed. All participants volunteered for the study, were healthy and had no neuromuscular disorders or orthopedic dysfunctions affecting hand strength. The research was conducted according to the postulates of the Declaration of Helsinki and with the permission of the Ethics Committee of the University of Belgrade Faculty of Sport and Physical Education (02 No. 484-2).

\section{B. Equipment}

Testing of the handgrip strength (i.e. maximal isometric muscle force $-\mathrm{F}_{\max }$ ) was performed using two measuring instruments - SMS HG system and a Jamar digital hand dynamometer (Fig.1.). The SMS HG system by Sports Medical Solutions, Belgrade, Serbia [23] was used for acquisition and in-depth analysis of the force signal, i.e. the F-t curve. The system measuring chain consisted of a load cell, an acquisition unit with integrated 12-bit A/D conversion and signal conditioning, and a laptop with installed SMS proprietary software. The employed load cell
(CZL301) was equipped with a full bridge strain gage sensor located on the "S" shaped deformation element. The external force applied to the deformation element causes a temporary strain-induced deformation of the material, thereby producing the same relative change in the length of the resistive elements of the bridge, thus causing the change in the measured output voltage value. The strain gage had a rated load of $200 \mathrm{~N}$, a maximum measurement error of $0.03 \%$, and linear dependence. The bridge was powered by a stabilized $10 \mathrm{~V}$ voltage. The sampling frequency of the system was $500 \mathrm{~Hz}$. Sensor calibration was performed using laboratory weights.

The Jamar isometric hand dynamometer DHD-3 (SH1003) developed by Seahan Corporation, Masan, Korea [24] with provided Certificate of Calibration by B\&L Engineering, Santa Ana, CA, USA was used as a reference instrument. The instrument employs a sealed hydraulic measurement system with declared measurement range $0-90 \mathrm{~kg}$ and accuracy $\pm 1 \%$ of full scale.

\section{Measurement methods}

All measurements were performed in the sitting position using two common protocols (elbow bent $90^{\circ}$ and elbow extended $180^{\circ}$ ) (Fig.1.) for both left and right hand. After the testing procedure was thoroughly explained and demonstrated, each participant was further familiarized with the procedure by performing two trial attempts with submaximal intensity. After a 5 min pause, the testing was carried out using a randomized trial-to-trial method with the pause duration of 3 minutes between the trials [25]. For each of the testing positions and measuring devices participants had two trials, and the better test result was taken for statistical processing. All results obtained using both measurement devices are presented in newtons $(\mathrm{N})$. All tests were performed at the University of Belgrade Faculty of Sport and Physical Education in Methodological Research Laboratory (MIL), between 09:00 and 11.30 AM.

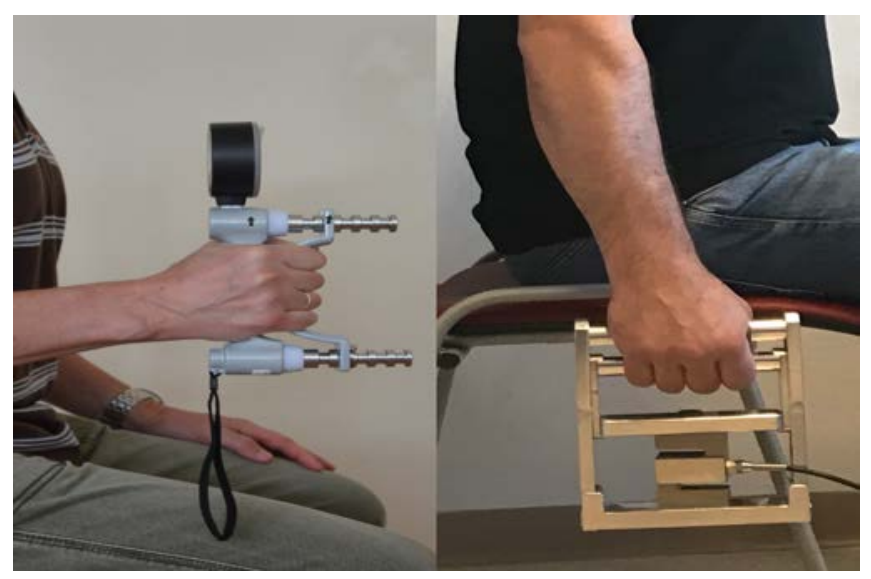

Fig.1. Jamar dynamometer and SMS HG strain gage used in positions of $90^{\circ}$ flexion and full extension in the elbow joint. 


\section{Variables}

The results obtained using SMS HG and Jamar instruments are presented in relation to relevant angles in the elbow joint $\left(90^{\circ}\right.$ and $\left.180^{\circ}\right)$ and in relation to results obtained on the Dominant hand (DH), Non-Dominant hand $(\mathrm{NDH})$, and Both hands $(\mathrm{BH})$. All results are expressed in newtons $(\mathrm{N})$.

\section{E. Statistical analysis}

For the purposes of this paper, all raw data was subjected to descriptive statistical analysis in order to define the basic indicators of central tendency (Mean) and data spread (Std. Dev, \% cV, Min, Max). Differences in the scores in relation to the testing position and concurrent validity of the instruments were evaluated using the paired samples t-test. Inter-instrument reliability was determined using the Intraclass Correlation Coefficient (ICC). A graphical method, the Bland-Altman plot, was used to evaluate the discrepancies between two measuring devices. The level of statistical significance was defined based on the criterion $\mathrm{p} \leq 0.05$ [26]. Statistical analyses were conducted using MS Excel 2013, IBM SPSS v23.0, and MedCalc v14.0 statistical software.

\section{RESULTS}

Descriptive data on handgrip strength results obtained in different positions in the elbow joint for both hands, dominant and non-dominant hand using the SMS HG dynamometric system and the Jamar digital dynamometer are shown in Table 1.

Table 1. Descriptive statistics for the SMS HG and Jamar dynamometers in relation to elbow angle and hand dominance.

\begin{tabular}{|l|c|c|c|c|c|c|}
\hline \multicolumn{7}{|c|}{ SMS HG } \\
\hline & $\mathrm{N}$ & $\begin{array}{c}\text { Mean } \\
(\mathrm{N})\end{array}$ & $\begin{array}{c}\text { SD } \\
(\mathrm{N})\end{array}$ & $\begin{array}{c}\% c V \\
(\%)\end{array}$ & $\begin{array}{c}\text { Min } \\
(\mathrm{N})\end{array}$ & $\begin{array}{c}\text { Max } \\
(\mathrm{N})\end{array}$ \\
\hline $90^{\circ} \_\mathrm{BH}$ & 122 & 395.01 & 118.40 & 29.97 & 208.0 & 720.0 \\
\hline $180^{\circ} \_\mathrm{BH}$ & 122 & 417.63 & 131.87 & 31.58 & 215.0 & 701.0 \\
\hline $90^{\circ} \_\mathrm{DH}$ & 61 & 408.71 & 120.00 & 29.36 & 228.0 & 720.0 \\
\hline $180^{\circ} \_\mathrm{DH}$ & 61 & 431.17 & 132.24 & 30.67 & 240.0 & 701.0 \\
\hline $90^{\circ} \_\mathrm{NDH}$ & 61 & 381.30 & 116.13 & 30.46 & 208.0 & 630.0 \\
\hline $180^{\circ} \_\mathrm{NDH}$ & 61 & 404.10 & 131.19 & 32.47 & 215.0 & 677.0 \\
\hline & \multicolumn{7}{|c|}{ Jamar } \\
\hline $90^{\circ} \_\mathrm{BH}$ & 122 & 421.33 & 113.87 & 27.03 & 232.5 & 715.1 \\
\hline $180^{\circ} \_\mathrm{BH}$ & 122 & 430.00 & 120.50 & 28.02 & 251.1 & 728.9 \\
\hline $90^{\circ} \_\mathrm{DH}$ & 61 & 433.68 & 115.71 & 26.68 & 232.5 & 715.1 \\
\hline $180^{\circ} \_\mathrm{DH}$ & 61 & 447.34 & 125.70 & 28.10 & 251.1 & 728.9 \\
\hline $90^{\circ} \_\mathrm{NDH}$ & 61 & 408.99 & 111.59 & 27.28 & 243.3 & 638.6 \\
\hline $180^{\circ} \_\mathrm{NDH}$ & 61 & 412.65 & 113.44 & 27.49 & 251.1 & 641.6 \\
\hline
\end{tabular}

Table 2. shows the results of the related samples t-test regarding the differences in handgrip strength scores obtained in different positions of the elbow joint using SMS HG and Jamar handgrip dynamometers.

Table 2. Pairwise comparisons of the handgrip strength scores in relation to used instrument and testing position.

\begin{tabular}{|c|c|c|c|c|}
\hline \multirow{4}{*}{ SMS HG } & $90^{\circ}-180^{\circ}$ & $\mathrm{df}$ & $\mathrm{t}$ & $\mathrm{p}$ \\
\hline & $\mathrm{BH}$ & 121 & -5.799 & 0.000 \\
\cline { 2 - 5 } & $\mathrm{DH}$ & 60 & -3.840 & 0.000 \\
\hline \multirow{3}{*}{ Jamar } & $\mathrm{NDH}$ & 60 & -4.371 & 0.000 \\
\cline { 2 - 5 } & $\mathrm{BH}$ & 121 & -3.307 & 0.001 \\
\cline { 2 - 5 } & $\mathrm{DH}$ & 60 & -4.066 & 0.000 \\
\cline { 2 - 5 } & $\mathrm{NDH}$ & 60 & -0.928 & 0.357 \\
\hline
\end{tabular}

Table 3. shows data regarding absolute (d) and relative differences (\% d), inter-reliability (ICC), and concurrent validity (Related samples t-test) of the SMS HG and the Jamar instruments in relation to different positions in the elbow joint for both hands, dominant and non-dominant hand.

Table 3. Comparison of the SMS HG vs Jamar dynamometer in relation to elbow angle and hand dominance.

\begin{tabular}{|l|c|c|c|c|c|}
\hline & $\mathrm{d}(\mathrm{N})$ & $\% \mathrm{~d}(\%)$ & $\mathrm{ICC}$ & $\mathrm{t}$ & $\mathrm{p}$ \\
\hline $90^{\circ} \_\mathrm{BH}$ & -26.33 & 6.25 & 0.951 & -5.610 & 0.000 \\
\hline $180^{\circ} \_\mathrm{BH}$ & -12.36 & 2.88 & 0.976 & -4.813 & 0.000 \\
\hline $90^{\circ} \_\mathrm{DH}$ & -24.97 & 5.76 & 0.948 & -4.158 & 0.000 \\
\hline $180^{\circ} \_\mathrm{DH}$ & -16.17 & 3.62 & 0.980 & -5.330 & 0.000 \\
\hline $90^{\circ} \_\mathrm{NDH}$ & -27.69 & 6.77 & 0.953 & -3.864 & 0.000 \\
\hline $180^{\circ} \_\mathrm{NDH}$ & -8.55 & 2.07 & 0.971 & -1.641 & 0.106 \\
\hline
\end{tabular}

Fig.2. shows the discrepancy of handgrip strength scores between SMS HG and Jamar instruments when measured in the testing position of $90^{\circ}$ flexion in the elbow joint.

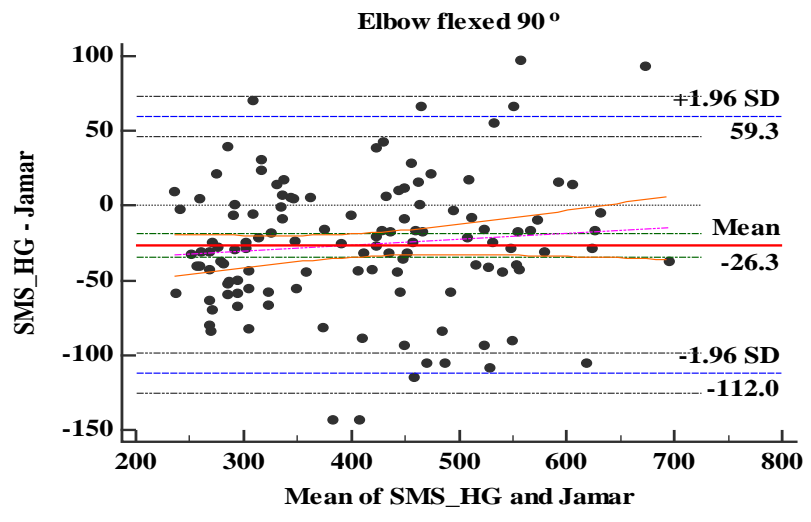

Fig.2. SMS HG vs Jamar Bland-Altman plot for $90^{\circ}$ flexion in the elbow joint. 
Fig.3. shows the discrepancy of handgrip strength scores between SMS HG and Jamar instruments when measured in the testing position of full extension in the elbow joint.

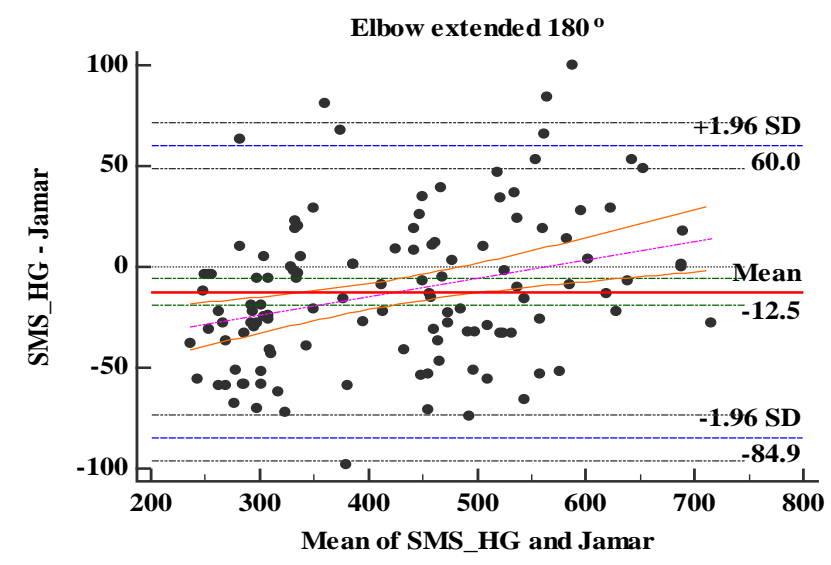

Fig.3. SMS HG vs Jamar Bland-Altman plot for $180^{\circ}$ extension in the elbow joint.

\section{DISCUSSION}

Considering the results obtained in the position of $90^{\circ}$ flexion in the elbow joint it was determined that the mean handgrip strength of the non-dominant hand was $381.30 \pm 116.13$ and $408.99 \pm 111.59 \mathrm{~N}$ measured with the SMS HG and Jamar instruments, respectively (Table 1.). The results obtained using the SMS HG instrument were on average $27.69 \mathrm{~N}$, i.e. $6.77 \%$ lower compared to those obtained using the Jamar dynamometer (Table 3.), and this difference was statistically significant $(t=-3.864, \mathrm{p}=0.000)$. The ICC of the results was at a high-reliability level of 0.953 with a $95 \%$ confidence interval from 0.851 to 0.979 $(\mathrm{F}=30.517, \mathrm{p}=0.000)$.

The mean handgrip strength of the dominant hand measured in the same position was 408.71 \pm 120.00 and $433.68 \pm 115.71 \mathrm{~N}$ for the SMS HG and Jamar instruments, respectively (Table 1.). The difference between the instruments was $5.76 \%(24.97 \mathrm{~N})$ with higher values obtained using the Jamar dynamometer. The difference between mean values was statistically significant ( $\mathrm{t}=-4.158$, $\mathrm{p}=0.000$ ) (Table 3.). The ICC value was highly reliable at 0.948 with a $95 \%$ confidence interval from 0.881 to 0.974 $(\mathrm{F}=24.266$, $\mathrm{p}=0.000)$.

When considering the results of both left and right hand obtained in the position $90^{\circ}$ flexion in the elbow joint, mean handgrip strength of $395.01 \pm 118.40 \mathrm{~N}$ was determined using an SMS HG strain gage, while the result of $421.33 \pm 113.87 \mathrm{~N}$ was determined using the Jamar digital dynamometer (Table 1.). The difference of the results was $6.25 \%$, i.e. $26.33 \mathrm{~N}$ with higher values determined using a Jamar dynamometer. The difference between mean values was statistically significant $(\mathrm{t}=-5.610, \mathrm{p}=0.000)$. The ICC of the results was also highly reliable at 0.951 with a $95 \%$ confidence interval from 0.878 to $0.975(\mathrm{~F}=27.273, \mathrm{p}=0.000)$ (Table 3.).
Based on the information above it can be concluded that the SMS HG strain gage and the Jamar digital dynamometer have a high level of inter-instrument reliability (ICC $\geq 0.948$ ) when considering the testing position of $90^{\circ}$ flexion in the elbow joint. The SMS HG strain gage consistently provides lower results than the Jamar instrument and these differences are statistically significant for all conditions $(p<0.05)$, which indicates the lack of concurrent validity. The percentage difference between the instruments determined for both hands was $26.33 \mathrm{~N}$, i.e. $6.25 \%$ and it is considered to have practical significance (Fig.1.). The lack of concurrent validity and practical significance of the differences between the obtained results indicates that the instruments cannot be used interchangeably.

Regarding the testing position of $180^{\circ}$ extension in the elbow joint, the mean handgrip strength score of the nondominant hand at the level of $404.10 \pm 131.19$ and $412.65 \pm 113.44 \mathrm{~N}$ was determined for the SMS HG and Jamar instruments, respectively (Table 1.). The mean difference was only $8.55 \mathrm{~N}$, i.e. $2.07 \%$, and it was not statistically significant $(\mathrm{t}=-1.641, \mathrm{p}=0.106)$. The ICC of the results was 0.971 with a $95 \%$ confidence interval from 0.951 to 0.983 ( $F=35.336, p=0.000$ ) (Table 3.).

The mean handgrip strength score of the dominant hand measured in the same position was $431.17 \pm 132.24 \mathrm{~N}$ using the SMS HG instrument and 447.34 $\pm 125.70 \mathrm{~N}$ using a Jamar dynamometer (Table 1.). The SMS HG instrument provided, on average, $16.17 \mathrm{~N}$ lower results than the Jamar dynamometer. The percentage of the difference between the instruments was $3.62 \%$. The difference was statistically significant $(\mathrm{t}=-5.330, \mathrm{p}=0.000)$. The ICC of the results was 0.980 with a $95 \%$ confidence interval from 0.956 to 0.990 ( $F=61.293, p=0.000)$ (Table 3.).

When comparing the results of both dominant and nondominant hand obtained in the testing position of $180^{\circ}$ extension in the elbow joint, the mean handgrip strength score of $417.63 \pm 131.87$ and $430.00 \pm 120.50 \mathrm{~N}$ was determined using an SMS HG strain gage and a Jamar dynamometer, respectively (Table 1.). The mean difference of the results was $12.36 \mathrm{~N}$, i.e. $2.88 \%$ and the SMS HG system provided lower scores. The difference was statistically significant $(\mathrm{t}=-4.813, \mathrm{p}=0.000)$. The ICC value was 0.976 with a $95 \%$ confidence interval from 0.962 to 0.984 ( $F=45.735, p=0.000)$ (Table 3.).

Regarding the position $180^{\circ}$ extension in the elbow joint, it can be concluded that SMS HG and Jamar instruments have a high level of inter-reliability (ICC $\geq 0.971)$. Statistically significant differences $(p<0.05)$ of the results were determined for both hands and the dominant hand. The difference between the instruments, when considering the non-dominant hand, was not statistically significant ( $>0.05)$. Overall, these results do not support the concurrent validity of the instruments. The percentage difference between the instruments determined for both hands was $12.36 \mathrm{~N}$, i.e. $2.88 \%$ and it is considered to have practical significance (Fig.2.). The lack of concurrent validity and practical significance [27] of the differences between the obtained results indicates that the instruments cannot be used interchangeably. 
The comparison of the handgrip strength scores in relation to the testing position has revealed statistically significant $(\mathrm{p} \leq 0.05)$ differences between results obtained in $90^{\circ}$ flexion and $180^{\circ}$ extension of the elbow joint, indicating that the results of the two positions cannot be directly compared even using the same equipment (Table 2.). The results obtained using the $180^{\circ}$ position were consistently higher across conditions (Table 1.). In relation to the differences in handgrip strength related to the elbow position, the findings of the present study are in line with [28] who determined significantly higher hand grip strength values in adolescents when using a TTK dynamometer and full extension in the elbow. Conversely, the same study determined that the difference between the two measurement positions is not significant when measured by Jamar or Dynex dynamometer. However, the full extension provided slightly higher results. A study by [4] determined significant differences in hand grip strength in relation to the examined elbow positions with higher values achieved using a full extension position and a Jamar dynamometer. Conversely, a study by [29] found no differences between the two elbow positions in healthy adults using an MIE digital grip analyzer. A study by [21] determined significantly higher values of handgrip strength in the position of full extension using a Jamar instrument. A reasonable explanation for the established differences in handgrip strength in relation to the elbow position is proposed by [4] and concerns the forcelength relationship of the involved muscles, namely the flexor digitorum superficialis (FDS), or more precisely its humeroulnar head which is connected to the medial epicondyle of the humerus via the common flexor tendon. As the FDS is the only primary finger flexor crossing the elbow joint it is possible that it is progressively placed in mechanical disadvantage caused by its shortening as the degree of flexion in the elbow joint increases, which causes the reduction in force output. Considering the findings that FDS accounts for more than $70 \%$ of the total force of all finger flexors when the point of force application is at the distal interphalangeal joint [30], this could account for the established differences. Another possible reason for the established handgrip strength differences in relation to the angle in the elbow joint is better stabilization of the wrist by the continuously coactivated extensor digitorum communis (EDC) and extensor carpi ulnaris (ECU), as well as other forearm muscles [31].

\section{CONCLUSION}

This study determined a lack of concurrent validity of the SMS HG strain gage system and the Jamar digital dynamometer for both examined testing positions, although a very high level of inter-instrument reliability $(\mathrm{ICC} \geq 0.948)$ [32], [33] was determined across conditions indicating that both devices accurately measure the same contractile characteristic of the relevant muscle groups. In addition, the present study established significantly higher handgrip strength results obtained in the position of full $\left(180^{\circ}\right)$ extension, compared to the position of $90^{\circ}$ flexion in the elbow joint using both measurement systems.

Thus, it can be concluded that:
The results obtained using the SMS HG strain gage measurement system and the Jamar digital dynamometer cannot be compared directly, i.e. the instruments cannot be used interchangeably.

The results obtained in different elbow positions cannot be directly compared even when the same measurement system is used.

\section{ACKNOWLEDGMENT}

The paper is a part of the project "Effects of the Applied Physical Activity on Locomotor, Metabolic, Psychosocial and Educational Status of the Population of the Republic of Serbia”, number III47015, funded by the Ministry of Education, Science and Technological Development of the Republic of Serbia - Scientific Projects 2011 - 2019 Cycle.

\section{REFERENCES}

[1] Zatsiorsky, V.M. (1995). Science and Practice of Strength Training. Human Kinetics.

[2] Kudrna, P., Tejkl, L., Rozanek, M. (2017). Electronic hand grip dynamometer. In E-Health and Bioengineering Conference (EHB). IEEE, 249-252.

[3] Tyldesley, B., Grieve, J.I. (1996). Muscles, Nerves, and Movement: Kinesiology in Daily Living, 2nd ed. Wiley-Blackwell.

[4] Vargo, E.A., Kuzala, M.C. (1992). The relationship between elbow position and grip strength. American Journal of Occupational Therapy, 46, 509-512.

[5] Balogun, J.A., Akomolafe, C.T., Amusa, L.O. (1991). Grip strength: Effects of testing posture and elbow position. Archives of Physical Medicine and Rehabilitation, 72 (5), 280-283.

[6] Dopsaj, M., Ivanovič, J., Blagojevič, M. et al. (2009). Basic and specific characteristics of the hand grip explosive force and time parameters in different strength trained population. Brazilian Journal of Biomotricity, 3 (2), 177-193.

[7] Bohannon, R.W. (2001). Dynamometer measurements of hand grip strength predict multiple outcomes. Perceptual and Motor Skills, 93 (2), 323-328.

[8] Marković, M.R., Dopsaj, M., Koropanovski, N., Ćopić, N., Trajkov, M. (2018). Reliability of measuring various contractile function of finger flexors of men of various age. Physical Culture (Belgrade), 72 (1), 37-48.

[9] Wind, A.E., Takken, T., Helders, P.J., Engelbert, R.H. (2010). Is grip strength a predictor for total muscle strength in healthy children, adolescents, and young adults? European Journal of Pediatrics, 169 (3), 281287.

[10] Ivanović. J., Dopsaj, M. (2012). Functional dimorphism and characteristics of maximal hand grip force in top level female athletes. Collegium Antropologicum, 36 (4), 1231-1240.

[11] Leyk, D., Gorges, W., Ridder, D. et al. (2007). Hand grip strength of young men, women and highly trained female athletes. European Journal of Applied Physiology, 99 (4), 415-421. 
[12] Marković, S., Dopsaj, M., Koprivica, V., Kasum, G. (2018). Qualitative and quantitative evaluation of the characteristics of the isometric muscle force of different muscle groups in cadet judo athletes: A gender-based multidimensional model. FACTA Universitatis Series: Physical Education and Sport, 16 (2), 245-260.

[13] Sayer, A.A., Kirkwood, T. (2015). Grip strength, and mortality: A biomarker of ageing? The Lancet, 386 (18), 226-227.

[14] Roberts, H.C., Denison, H.J., Martin, H.J. et al. (2011). A review of the measurement of grip strength in clinical and epidemiological studies: Towards a standardised approach. Age and Ageing, 40 (4), 423429.

[15] Innes, E. (1999). Handgrip strength testing: A review of the literature. Australian Occupational Therapy Journal, 46 (3), 120-140.

[16] Mirkov, D., Nedeljkovic, A., Milanovic, S., Jaric, S. (2004). Muscle strength testing: Evaluation of tests of explosive force production. European Journal of Applied Physiology, 91 (2-3), 147-154.

[17] Dopsaj, M., Mijalkovski, Z., Vasilovski, N., Copic, N., Brzakovic, M., Markovic, M. (2018). Morphological parameters and handgrip muscle force contractile characteristics in the first selection level in water polo: Differences between U15 water polo players and the control group. Human. Sport. Medicine, 18 (3), 5-15.

[18] Murugan, S., Patel, D., Prajapati, K., Ghoghari, M., Patel, P. (2013). Grip strength changes in relation to different body postures, elbow and forearm positions. International Journal of Physiotherapy and Research, 1 (4), 116-121.

[19] Hillman, T.E. Nunes, Q.M., Hornby, S.T. et al. (2005). A practical posture for hand grip dynamometry in the clinical setting. Clinical Nutrition, 24 (2), 224-228.

[20] Mathiowetz, V., Rennells, C., Donahoe, L. (1985). Effect of elbow position on grip and key pinch strength. The Journal of Hand Surgery, 10 (5), 694697.

[21] Su, C.-Y., Lin, J.-H., Chien, T.-H., Cheng, K.-F., Sung, Y.-T. (1994). Grip strength in different positions of elbow and shoulder. Archives of Physical Medicine and Rehabilitation, 75 (7), 812-815.
[22] Thomas, J., Nelson, J., Silverman, S. (2015). Research Methods in Physical Activity, 7th ed. Human Kinetics.

[23] All4gym d.o.o.; http://all4gym.rs/.

[24] SAEHAN Corp.; http://www.saehanmedical.com/sub/ eng/main/main.html.

[25] Tanner, R., Gore, C. (2012). Physiological Tests for Elite Athletes, 2nd ed. Human Kinetics.

[26] Hair, J, Anderson, R., Tatham, R., Black, W. (1998). Multivariate Data Analysis With Readings, 5th ed. Prentice-Hall.

[27] Mathiowetz, V., Vizenor, L., Melande, D. (2000). Comparison of baseline instruments to the Jamar dynamometer and the B\&L engineering pinch gauge. OTJR Occupation Participation Health, 20 (3), 147162.

[28] España-Romero, V., Ortega, F.B., Vicente-Rodríguez, G. et al. (2010). Elbow position affects handgrip strength in adolescents: Validity and reliability of Jamar, DynEx, and TKK dynamometers. Journal of Strength and Conditioning Research, 24 (1), 272-277.

[29] Shyam Kumar, A.J., Parmar, V., Ahmed, S., Kar, S., Harper, W.M. (2008). A study of grip endurance and strengh in different elbow positions. Journal of Orthopaedics and Traumatology, 9 (4), 209-211.

[30] Su, C.-Y., Lin, J.-H., Chien, T.-H., Cheng, K.-F., Sung, Y.-T. (1994). Grip strength in different positions of elbow and shoulder. Archives of Physical Medicine and Rehabilitation, 75 (7), 812-815.

[31] Li, Z.-M., Zatsiorsky, V.M., Latash, M.L. (2001). The effect of finger extensor mechanism on the flexor force during isometric tasks. Journal of Biomechanics, 34 (8), 1097-1102.

[32] Johanson, M.E., James, M.A., Skinner, S.R. (1998). Forearm muscle activation during power grip and release. The Journal of Hand Surgery, 23 (5), 938-944.

[33] Vincent, W. (2005). Statistics in Kinesiology, 3rd ed. Human Kinetics.

[34] Koo, T.K., Li, M.Y. (2016). A guideline of selecting and reporting intraclass correlation coefficients for reliability research. Journal of Chiropractic Medicine, 15 (2), 155-163.

Received September 9, 2019

Accepted March 10, 2020 